Anales de Historia del Arte

ISSN: 0214-6452

http://dx.doi.org/10.5209/ANHA.57486

\title{
Francisco Manso, platero madrileño del siglo XVII
}

\author{
Laura Illescas Díaz'; Ignacio José García Zapata
}

Recibido: 28 de febrero de 2017 / Aceptado: 8 de mayo de 2017

Resumen. No son pocas las ocasiones en las que revisando los fondos de un archivo encontramos de manera fortuita alguna escritura o legajo que, si bien resultan ajenos a nuestra investigación, son de gran interés y los aparcamos para un estudio posterior. Ocurrió así con el testamento, inventario y almoneda de Francisco Manso, platero activo en Madrid durante la segunda mitad del XVII. Hasta el momento, ha resultado bastante desconocido, y prueba de ello es la falta de referencias sobre su trayectoria vital y profesional. Sin embargo, el análisis de la documentación conservada en el Archivo Histórico de Protocolos de Madrid cambiará su suerte, pues nos permitirá conocer, entre otras cuestiones, sus orígenes, su posición económica y su círculo más cercano. Así pues, con la siguiente lectura, no sólo tendremos la oportunidad de acercarnos con más detalle a su figura, sino de avanzar en el conocimiento del conjunto de maestros del Arte de la Platería en el Madrid del Seiscientos.

Palabras clave: platería; Madrid; Manso; testamento.

\section{[en] Francisco Manso, Silversmith of Madrid from the $17^{\text {th }}$ Century}

Abstract. Sometimes, when we check the funds of a archive, we find, fortuitously, some writing that, although they are not linked to our main research, are very interesting for other studies. This happened with the testament, inventory and almoneda of Francisco Manso, active silversmith in Madrid during the second half of the 17th century. So far, he has been quite unknown, and the proof is the lack of references on his life and professional trajectory. However, the analysis of the documentation preserved in the Historical Archives of Protocols of Madrid will change their fate, as they will allow us to know, among other issues, his origins, economic situation and his closest circle. Thus, with the following reading, not only will we have the opportunity to approach in more detail his figure, but also to advance in the knowledge of the set of masters of the Art of the Silver in the Madrid of the 17th century

Keywords: Silverware; Madrid; Francisco Manso; Testament.

Sumario: 1. Biografía. 2. Sus últimas voluntades. 3. Sus bienes: inventario y almoneda.

Cómo citar: Illescas Díaz, L.; García Zapata, I.J. (2017): Francisco Manso, platero madrileño del siglo XVII, en Anales de Historia del Arte 27, 169-181.

\footnotetext{
1 Universidad de Salamanca

E-mail: egelesta@gmail.com

2 Universidad de Murcia. Departamento de Historia del Arte

E-mail: ignaciojose.garcia@um.es
} 


\section{Biografía}

Francisco Manso era natural de la villa de Belorado (Burgos), hijo de Francisco Manso y María Pascual, desconociéndose su fecha de nacimiento dado que, en la documentación estudiada, no hay ninguna mención a su edad ${ }^{3}$. Si bien, para la década de 1660 ya estaba trabajabajando en suelo madrileño, lo que indica que tuvo que nacer durante la primera mitad del siglo $\mathrm{XVII}^{4}$. Manso contrajo matrimonio con Jerónima de Villanueva, con quien tuvo seis hijos, cuatro de los cuales tomaron los votos: Francisco Manso, clérigo de la parroquia de Santiago de los españoles en Roma; María y Catalina Manso, ambas monjas del convento de Santa Catalina de Siena en Alcalá de Henares 5 , y, por último, el pequeño de los hermanos, Simón, quien al parecer se hallaba por aquel tiempo estudiando la carrera eclesiástica. A estos debemos sumar los dos restantes, Jerónima, casada con el platero Juan Montero de Espinosa, y Manuel Manso, quien continuó la profesión del padre, siendo platero de oro y tasador de joyas de la Cámara Real desde 1690, fecha en la que aceptó dicho cargo mediante juramento ante el duque de Pastrana y del Infantado ${ }^{6}$.

Fue feligrés de la parroquia de San Miguel de los Octoes, donde pidió ser enterrado con el hábito de San Francisco junto a su esposa ${ }^{7}$, si bien era más frecuente que los plateros pertenecieran a la parroquia de San Salvador, debido a su proximidad con la sede de la corporación de San Eloy ${ }^{8}$. Al igual que el resto de sus conciudadanos, par-

3 Entre los diversos estudios que hemos consultado con el propósito de dar con alguna referencia suya se encuentran: DEL CORRAL, José, "Plateros madrileños en los años centrales del Siglo de Oro", Anales del Instituto de Estudios Madrileños, 45 (2005), pp. 95-94 y AGULLÓ COBO, Mercedes, "Plateros madrileños en los siglos XVI y XVII", Anales del Instituto de Estudios Madrileños, 46 (2006), pp. 1003-1014. Pese a que el contenido ofrecía la posibilidad de ejecutar un estudio de mayor profundidad, dada las limitaciones de este artículo, centraremos nuestra atención única y exclusivamente en dos de los documentos antes mencionados, el testamento y el inventario. Así, con los datos inéditos que de ellos hemos extraído lograremos acercarnos a la figura de este artífice aún desconocido, que a su vez nos resultará clave para profundizar en el conocimiento de la platería madrileña barroca, tan estudiada por los profesores José Manuel Cruz Valdovinos y Carmen Heredia Moreno, entre muchos otros.

4 En 1662 se documenta la primera noticia que existe del burgalés en Madrid. Véase en: GARCÍA LÓPEZ, David, "Joyería y platería en la Casa de Béjar, 1660- 1677. Las compras de la duquesa doña Teresa Sarmiento de la Cerda, IX duquesa de Béjar”, en RIVAS CARMONA, Jesús (coord), Estudios de Platería: San Eloy 2006, Murcia, Editum, p. 243.

5 Como tendremos la oportunidad de ver más adelante, a esta comunidad de religiosas también pertenecían sor Ángela de San Pablo y sor Inés de San Francisco, primas de la esposa de Francisco Manso.

6 ARANDA HUETE, Amelia María, La joyería en la Corte durante el reinado de Felipe Ve Isabel de Farnesio, Tesis doctoral, Universidad Complutense de Madrid, 2004, p. 423.

$7 \quad$ "Y cuando su divina magestad fuere servido de llevarme de esta presente bida sea amortajado con el avitto de mi seraphico padre san francisco por ser hermano de su therzera orden de penitencia aunque indigno, $y$ sepultado en la Yglesia parroquial de san Miguel de esta dicha villa en la sepoltura propia que tengo junto al púlpito dónde está enterrada doña Gerónima de Villa nueba". Véase Archivo Histórico de Protocolos de Madrid (en adelante A.H.P.M.) Protocolo n ${ }^{\circ}$ 10973, fol. 948 v. El hábito de San Francisco era considerado en aquel momento el más idóneo para reflejar el espíritu de pobreza del fallecido. Fue indudablemente el hábito más popular, siendo solicitado durante el siglo XVII por más de dos tercios del total demandado. El motivo principal de este arraigo es, además del mensaje de pobreza y humildad que se pretendía transmitir, el valor de las indulgencias concedidas por tres papas, Nicolás IV, León X y Clemente VII. Para un estudio más profundo, véase GARCÍA FERNÁNDEZ, Máximo, Los castellanos y la muerte: religiosidad y comportamientos colectivos en el Antiguo Régimen, Valladolid, Junta Castilla y León, 1996.

8 Los plateros madrileños tenían su asiento en la Iglesia de San Miguel de Octoes, donde contaron ya desde el siglo XVI con una imagen del santo titular de la cofradía, San Eloy. Dicho templo fue uno de los más antiguos de la Villa -su nombre aparece citado en el fuero de Madrid por primera vez en el año 1202- y se mantendrá muy unido al linaje de los Zapata durante los siglos XV, XVI, y XVII. Fue demolido en el 1791 por orden de Juan de 
ticipó del espíritu religioso del momento y, además de pertenecer a la ya mencionada cofradía de San Eloy, fue miembro de la Congregación mariana de Nuestra Señora de la Natividad en la Casa Profesa, fundada en el año 1630 para materializar así el deseo de los jesuitas ${ }^{9}$. Allí debió practicar una intensa actividad devocional basada en la penitencia de los pecados, en el asiduo cumplimiento de los sacramentos, en la oración y en la realización de obras de piedad ${ }^{10}$.

Respecto a su trayectoria profesional y artística cabe decir que las noticias publicadas son casi inexistentes, circunstancia a la que desafortunadamente debemos añadir la ausencia de referencia alguna a sus encargos en la documentación manejada. No obstante, la inclusión en el testamento del distinguido platero Manuel Mayers como albacea ${ }^{11}$, en quien depositó absoluta confianza, no sólo para la administración de sus bienes sino también para el cuidado de su hijo menor (lo nombró su tutor en caso de fallecer), deja entrever el estrecho vínculo entre ambos artistas, útil para vislumbrar los círculos en los que se movía Manso. Y es que el hecho de relacionarse con semejante personalidad conduce a pensar que su actividad profesional se desarrolló en ambientes muy cercanos a la corte, como confirma la corona de plata que realizó para la imagen de Nuestra Señora de la Concepción ${ }^{12}$, propiedad de Teresa Sarmiento de la Cerda, IX duquesa de Béjar ${ }^{13}$.

Villanueva, tras resultar gravemente dañado por el incendio ocurrido un año antes en la Plaza Mayor, vease en: MARTÍN TOVAR, Cristóbal, "La iglesia madrileña de San Miguel de los Octoes y su entorno urbano", Anales de Historia del Arte, 8 (1998), pp. 149 -170. Si bien, durante el siglo XVII la corporación madrileña se trasladó a su nueva capilla en la Iglesia de San Salvador, donde erigieron un retablo para el cual encargaron al escultor Sebastián de Bejarano una nueva imagen de San Eloy, vease en: CRUZ VALDOVINOS, José Manuel, Los plateros madrileños. Estudio histórico-jurídico de su organización corporativa, Madrid, Gremio de Joyeros y Plateros de Madrid, 1983.

9 Los jesuitas, propagadores de este del culto a María, desearon con gran ímpetu la formación de una congregación para tal fin. Véase en MARÍN BARRIGUETE, Fermín, "Los jesuitas y el culto mariano: la Congregación de la Natividad en la Casa Profesa de Madrid", Tiempos modernos: Revista Electrónica de Historia Moderna, 9 (2003), p. 1

10 Ibídem, p. 1

11 Sobre este platero del siglo XVII, véase: BARRIO MOYA, José Luís, "La librería de Manuel Mayers Caramuel, contraste de oro y plata de Felipe IV y Carlos II (1693)", Cuadernos para Investigación de la Literatura Hispánica, 21 (1996), pp. 181-210.

12 GARCÍA LÓPEZ, David, “Joyería y platería ...”, op. cit., p. 243.

13 Perteneciente a una de las casas nobiliarias con mayor poder, la viuda de Juan Manuel de Zúñiga se caracterizó por un refinado gusto por el arte que materializó no sólo en la adquisición de obras - pinturas, esculturas, tapices...- sino con su propia práctica, siendo alumna incluso de Francisco Ricci, quien le dedicó su tratado de Pintura Sabia. Gracias a los registros conservados de los gastos que protagonizó la duquesa desde el 15 de noviembre de 1660 al año 1677, anotados por el contador de la casa de Béjar, Miguel del Valle, vio la luz esta curiosa noticia que nos habla del reconocimiento que alcanzó nuestro platero, demandando su maestría las clases más selectas del momento. para el estudio de su figura, véanse, entre otros trabajos: GARCÍA LÓPEZ, David, "La IX duquesa de Béjar doña Teresa Sarmiento y el monasterio de franciscanas de la purísima Concepción de Caballero de Gracia. Las mujeres y la práctica de la pintura en la España del siglo XVII", en $L a$ clausura femenina en el Mundo Hispánico: una fidelidad secular: Simposium (XIX Edición) San Lorenzo del Escorial, Madrid, Real Centro Universitario Escorial - María Cristina, 2011, pp. 865- 884; GARCÍA LÓPEZ, David, Arte y pensamiento en el Barroco. Fray Juan Andrés Ricci de Guevara (1600- 1681), Madrid, Fundación Universitaria Española, 2010. 


\section{Sus últimas voluntades}

En su testamento, realizado con total uso de razón, Francisco Manso siguió el canon establecido ${ }^{14} \mathrm{y}$ dedicó una primera parte a todo lo concerniente al ámbito espiritual: comenzó por la demanda de misas con la que perseguía, junto con otros medios, descargar la conciencia y limpiar el alma de tormentos. Solicitó que celebrasen honras en su honor en la Casa Profesa, concretamente en la bóveda de Nuestra Señora de la Natividad, donde se dirían "todas las misas que se pudieren decir (...) a razón de dos reales de plata para cada una"15. A ellas añadió otras seis, repartidas en dos de las parroquias de mayor relevancia de Madrid, la de Santiago y la del convento de Nuestra Señora de Atocha. Finalmente, pidió que durante los nueve días de su novenario se dijera "misa cantada con diácono y subdiácono y responsso en mi sepultura en la iglesia de San Miguel"16. Una vez que aseguró su propia salvación se encargó de socorrer las almas de sus familiares difuntos, por las que pidió a los testamentarios que celebrasen misas con el remanente del quinto de sus bienes, dejando a su propia elección la parroquia donde tendrían lugar ${ }^{17}$.

Acorde con la conducta del buen cristiano, continuó cediendo parte de su patrimonio a la Iglesia; ofreciendo seis reales de vellón a las mandas forzosas y veinte reales de vellón a los Santos Lugares de Jerusalén. Por último, hizo entrega de cien reales de vellón al Santo Cristo de la parroquia de San Miguel "para ayuda de su altar" "18; cincuenta ducados de vellón para Nuestra Señora de la Natividad de la Casa Profesa y diez ducados de vellón para ayuda de "su adorno" del Santo Cristo de los Dolores de la Orden Tercera, advocación bajo la cual se encontraba la capilla proyectada por el hermano Francisco Bautista y Sebastián Herrera Barnuevo, adosada al convento de San Francisco el Grande ${ }^{19}$. En definitiva, el platero, tal y como era la tónica general, destinó parte de sus bienes a la Iglesia con el deseo de preservar su alma una vez fallecido.

Una vez solventadas las cuestiones espirituales, se encargó de velar por aquellas concernientes a su patrimonio terrenal; éste alcanzaba la suma de "dos mill doscientos y veyntte doblones de oro de a dos escudos en platta labrada joyas perlas diamantes alaxas y bienes muebles y effectos que se me deben y zinco mil ducados de vellón y reputados los doblones a zincuenta por cientto el premio de la plata azencientto y seis mill quinientos y sesenta reales de vellon con que biene a montar toda mi hazienda" "20. Dicha cantidad refleja la holgada posición económica del artista, la cual repercutió en parte en la Iglesia, como ya hemos visto, y en su familia. En pri-

14 El testamento está incluido en el protocolo perteneciente al escribano Vicente Suárez, no está fechado ni porta la firma de tal escribano, tan sólo una nota en la parte final en la que se nos informa de que existió otro testamento realizado ante el escribano real Juan de Belarrinaga el 19 de abril de 1675, cuyo intento de localización ha sido infructuoso hasta el momento. Así, sabemos con certeza la fecha exacta de su fallecimiento, acaecido según sus herederos el 7 de junio de 1678. A.H.P.M. Protocolo $n^{\circ}$ 10973, fol. 960 r.

15 A.H.P.M. Protocolo n ${ }^{\circ} 10973$, fol. 948 v.

16 A.H.P.M. Protocolo n ${ }^{\circ} 10973$, fol. 950 r.

17 A.H.P. M. Protocolo ${ }^{\circ} 10973$, fol. 956 v.

18 A.H.P.M. Protocolo $n^{\circ} 10973$, fol. 957 r.

19 En ella se custodiaba, entre otras piezas, una de las numerosas versiones que ejecutó del Cristo de los Dolores el jesuita Domingo de Rioja, pintor y escultor del XVII. Véase BONET SALAMANCA, Antonio, "El templo de San Francisco el Grande de Madrid”, en El culto a los santos: cofradias, devoción, fiestas y arte, Madrid, Ediciones Escurialenses, 2008, p. 922

20 A.H.P.M. Protocolo n ${ }^{\circ} 10973$, fol. $950 \mathrm{v}$. 
mer lugar hizo referencia a las particiones de "los bienes y hacienda que (Jerónima de Villanueva) dejó entre mi y sus seis hijos y mios que fue approbada por el señor lizenciado Don Juan Lucas Cortes" el 13 de agosto de 1672 en la villa de Madrid, tocándole a cada uno de los herederos "asta dos mill y quinientos ducados poco mas $o$ menos"21. Tras esta puntualización, comenzó entregando a sus hijas, sor María de Santo Domingo y sor Catalina de San Jerónimo ${ }^{22}$, una renta de cien ducados de renta al año, "cincuenta a cada una para que los goçasen por todos los dias de sus bidas y un año despues para el dicho conbentto para que hiziesen bien por sus almas"23. En caso de fallecer una de las dos, la que le sobreviviese, poseería el derecho de heredar la cantidad correspondiente a su hermana hasta que ésta también falleciera, momento a partir del cual, la renta, como bien se especifica en la escritura, sería entregada a la priora y religiosas del convento de Santa Catalina de Siena durante un año. Además, les hizo entrega de una "cama de nogal con su colgadura de lana y seda con sus cortinas cobertor", unas sortijas y varias piezas de devoción privada, "un santo cristo de oro con su cruz de madera, y una cruz de oro con otra cruz de madera encajada dentro y un relicario de oro con un lignun crucis (...), un santo Christo de madera metido en una caja que está en mi aposento (...), y una cuenta de santa Juana de la Cruz guarnezida de oro con su cadena de lo mismo"24. Este conjunto de piezas, al igual que especifica en el caso de las rentas, serían heredadas de una a la otra en caso de fallecimiento.

Continuó con el reparto de sus bienes entre el resto de hijos y familiares más cercanos. A su hijo menor, Simón Manso, le dejó entregados cien ducados de vellón "para ayuda de sus estudios", idéntica cantidad que estipuló para su hija Jerónima Manso, esposa del ya mencionado Juan Montero de Espinosa, a quien también le entregó un “arcabuz largo con su frasco". A su hijo platero, Manuel Manso, además de las rentas, le dejó "un santo Cristo que esta encima de el escritorio encarnado con su peana que es la alaja que mas estimo y una carabina larga de bara" 25 . A su cuñada Francisca de Villanueva ${ }^{26}$, viuda de Adrián de Luca, legó cien ducados de vellón y "una docena de servilletas, dos tablas de manteles media docena de paños de manos y dos colchones con su lana de los que se allaren en mi cassa". A su hermana, María Pascual, natural como él de la villa de Belorado, le entregó cien ducados, los cuales heredaría su hija habida con Juan de Mojoncillo, María Calvo, en caso de fallecer la dicha María Pascual antes que él. Las ya mencionadas primas de su esposa, Ángela de San Pablo e Inés de San Francisco, ambas monjas profesas, recibieron de Francisco Manso cincuenta ducados de vellón cada una. Idéntica cantidad dejó por herencia a las tres hijas de María de Arcilla y su difunto marido, Francisco Payan ${ }^{27}$.

\footnotetext{
A.H.P.M. Protocolo n ${ }^{\circ}$ 10973, fol. 951 r.
}

22 Como venía siendo habitual, tras tomar los hábitos, las hijas de Francisco Manso renunciaron a su herencia patrimonial el 3 de enero de 1674 en la villa de Alcalá de Henares, ante el escribano Luis de Lofre. A.H.P.M. Protocolo no 10973 , fol. 952 r.

23 A.H.P.M. Protocolos n ${ }^{\circ} 10973$, fol. $952 \mathrm{v}$

24 A.H.P.M. Protocolo n ${ }^{\circ} 10973$, fol. 954 v.

25 En una de las cláusulas especifica que le tiene prestado "novecientos y cincuenta y seis doblones de oro de a dos escudos" sin especificar las razones por las cuales el hijo necesitaba tal cantidad. A.H.P.M. Protocolo n ${ }^{\circ} 10973$, fol. $956 \mathrm{r}$.

26 En el testamento se dirige a ella como "mi hermana que esta en mi casa", si bien suponemos que se trata de un error dado que con ese apellido sólo puede tratarse de la hermana de su mujer, es decir, su cuñada.

27 Fallecido Francisco Payán, quien nos resulta del todo desconocido, María de Arcilla parece ser que volvió a contraer matrimonio, siendo el elegido Manuel Manso, el platero de oro y tasador de joyas de la Corona; 
Por último, nombró a Francisca Cañeque, su criada", a la que "si a la sazon estubiere en mi cassa de mi fallezimiento (se entregue) una cama de ropa y zinqueta ducados de vellon para ayuda de tomar estado"29.

Una vez concluido este generoso reparto de bienes entre los más cercanos, atendió las necesidades de los familiares de sus antiguos compañeros de profesión cuya situación económica no debía ser muy boyante. Así, hizo entrega de veinte ducados de vellón a los siguientes destinatarios. La hija de Alonso el cadenero, María Alonso; la viuda de Juan Bautista Tomassin; y por último viuda de Lorenzo de Espinar, especificando que, en caso de que alguna de las tres falleciese antes que él, "la cantidado cantidades que fuere se entregue a los mayordomos de la congregación de san Eloy de los plateros de esta corte para que los repartan entre los pobres de la platteria" 30 . No olvidó a los plateros Joseph del Río y Mario de Soria entre quienes fueron repartidos "todos los vestidos mios que se hallaren al tiempo de mi muerte" 31 , hecho que demuestra el cumplimiento por Francisco Manso de los postulados del gremio, entre los que se incluía, como hemos podido comprobar en esta última cláusula de su testamento, destinar recursos para el socorro y ayuda de aquellos maestros menos favorecidos.

Nombró como albaceas a Manuel Mayers, Pedro de Tudela, Pedro de Nieva, Francisco y Manuel Manso -sus hijos- y Juan Montero de Espinosa, en quienes depositó absoluta confianza y les dio "poder y facultad sin limitación alguna con libre y general administración y relevación para que hagan recuento de todos mis bienes y los vendan en almoneda publica o fuera de ella y de su balor cunplan y ejecuten este mi testamento aunque sea pasado el año del albaceazgo"32. Se dirigió una vez más a Manuel Mayers, a quien, como ya anticipamos, nombró "tutor y curador" de su hijo menor Simón, encargándole y suplicándole que "por amor de Dios acepte el cargo para que con su ejemplo se crie bien y prosiga con los estudios "33; no obstante, en el caso de no poder hacer frente a su tutela dadas sus numerosas ocupaciones, eligió como sustituto a Francisco Barba, confitero, de modo que el pequeño no quedase desamparado.

Una vez que fueran cumplidas todas las disposiciones, Francisco Manso estipuló que el remanente fuera repartido igualmente con la bendición de Dios entre sus herederos universales, Manuel, Simón y Jerónima, quedando excluidos los hermanos que tomaron los votos ${ }^{34}$. No obstante, hizo una excepción con el varón, es decir con Francisco, especificando que, a pesar de haber hecho donación de las legítimas paterna y materna, se incluiría como un heredero más en el caso de que llegase a pasar necesidades, sin extender esta prerrogativa a las hermanas residentes en el convento de Alcalá de Henares, a quienes excluyó en la partición de su patrimonio.

El citado testamento se materializó tres años después, cuando el artífice falleció en 1678. Tal y como había previsto en la testamentaria, su hijo Manuel y su yer-

así pues, las tres hijas de esta mujer a las que hace referencia Francisco Manso en su testamento serían sus nietastras. A.H.P.M. Protocolo n ${ }^{\circ} 10973$, fol. 955 v.

28 A.H.P.M. Protocolo n ${ }^{\circ} 1014$ v.

29 A.H.P.M. Protocolo $n^{\circ} 10973$, fol. 956 r.

30 A.H.P.M. Protocolo $n^{\circ} 10973$, fol. $955 \mathrm{v}$.

31 A.H.P.M. Protocolo $\mathrm{n}^{\circ} 10973$, fol. $955 \mathrm{v}$.

2 A.H.P.M. Protocolo $n^{\circ}$ 10973, fol. 957 r.

A.H.P.M. Protocolo $n^{\circ}$ 10973, fol. 958 r.

44 A.H.P.M. Protocolo $n^{\circ}$ 10973, fol. 957 v. 
no Francisco Espinosa fueron los responsables de velar por el cumplimiento de lo dispuesto por Manso, de modo que para llevar a cabo su voluntad se dispusieron a inventariar y tasar los bienes que el maestro platero había legado a sus familiares, acción para la que necesitaron la aprobación del hermano menor de edad, Simón, quien por supuesto rubricó con su firma el inicio del proceso ${ }^{35}$. Éste fue iniciado por el teniente corregidor de la villa de Madrid, Jerónimo Pelegrin, quien designó a Manuel Martínez curador ad litem del hermano menor de edad para defender sus intereses y, por tanto, el correcto cumplimiento del testamento del platero ${ }^{36}$. Por su parte, Francisco Manso, hijo del padre de nombre homónimo y presbítero en Roma, envió una misiva bajo notario a través de la cual renunciaba a todo aquello que le correspondía en testamento si los hermanos se hacían cargo de pagar una serie de letras. Juan Carrillo Vallejo, notario y secretario de la Iglesia y Hospital de Santiago y San Ildefonso de Roma, fue el encargado de dar forma a la petición. En primer lugar, Manso hijo reconocía que en el año 1674 su padre le había hecho una donación en base a las legítimas paterna y materna, y por ello, tal y como había establecido su progenitor, solo en caso de que el clérigo se hallase en suma necesidad podría entrar a forma parte de la partición y reparto de los bienes. La situación del presbítero en Roma era de necesidad, por encontrarse enfermo, sin medios y sin la decencia necesaria. No obstante, y a pesar de la acuciante situación, renunció en favor de sus hermanos a cualquier tipo de derecho o acción sobre los bienes legados. Si bien, puso un requisito fundamental para cerciorar su renuncia al patrimonio: los hermanos, sin ningún tipo de dilación debían pagar dos letras, la primera de cuarenta y dos escudos de oro, para hacer frente al compromiso que el maestro platero había adquirido un año antes, deuda que había que pagar a Jacome Gratiani por la cantidad que en Roma había recibido su hijo de parte de Baltasar Gómez. La otra letra era de una cantidad mayor, cien escudos de oro, y debía de pagarse al mismo Baltasar Gómez, quien debió de ser un prestamista o acreedor del presbítero español en Roma ${ }^{37}$.

\section{Sus bienes: inventario y almoneda}

En su testamento Manso dejó un importante legado cuyas características reflejan la acomodada posición que tenía dentro de la sociedad madrileña de aquel entonces. No obstante, este desahogo económico podría justificarse, además de por su oficio como platero, por la administración de otros negocios, una práctica muy habitual ${ }^{38}$, lo que le permitiría disponer del estatus económico que se hace palpable en el inventario de sus bienes. De este modo, y para cumplir con una correcta valoración de los mismos, la familia del platero contactó con una serie de personas destinadas a tasarlos en función de su especialidad ${ }^{39}$. En primer lugar, contaron con la importante

\footnotetext{
A.H.P.M. Protocolo $n^{\circ}$ 10973, fol. $960 \mathrm{r}$ y v.

A.H.P.M. Protocolo $n^{\circ} 10973$, fol. $960 \mathrm{v}$ a $962 \mathrm{r}$.

A.H.P.M.. Protocolo n ${ }^{\circ} 10973$, fol. 1007 r a 1008 r.

38 En Murcia, por ejemplo, numerosos maestros del Arte de la Platería se dedicaban al comercio de la hoja moreral, a la venta de esclavos y al arrendamiento de tierras de cultivo, siendo el caso más notable el de Antonio Gozalbo, ver: GARCÍA ZAPATA, Ignacio José, "El platero Antonio Gozalbo Llaudéns y la custodia de la parroquia de San Lázaro Obispo de Alhama de Murcia”, en RIVAS CARMONA, Jesús (coord.), Estudios de Platería: San Eloy 2014, Murcia, Editum, 2014, pp. 187-202.

39 A.H.P.M. Protocolo n ${ }^{\circ}$ 10973, fol. 980 r.
} 
contribución del ya mencionado Manuel Mayer. Por su parte, las pinturas fueron consignadas a Andrés de Esmitte, quien posiblemente se trate del pintor flamenco Andrés Smidt, por entonces activo en Madrid ${ }^{40}$. En cuanto al mobiliario, el elegido fue Eugenio Martín Ricote, ebanista, y para los vestidos y ropa en general se acudió al sastre Luis Portero, si bien, las cosas tocantes a la ropa blanca se dejaron a cargo de Eugenia de Enciso, mujer del platero Juan Cano. En este sentido, por la evidente afinidad, el encargado de valorar los útiles del oficio de nuestro artista, así como todo lo concerniente al mismo, fue el platero madrileño Juan de Orea, maestro que ya se había ocupado de esta tarea en otras ocasiones ${ }^{41}$.

Como ya se ha adelantado, el inventario consta de una extensa lista de bienes que permiten dilucidar con toda claridad la alta capacidad adquisitiva del platero. Este hecho queda patente en un primer momento ante el sustancioso número de muebles y demás objetos vinculados a este campo que se conservaban en su casa. Por ejemplo, hay que destacar la presencia de varias camas, escritorios, bufetes, mesillas, sillas, espejos, escaparates, aparadores, arcas y demás, de todas las formas, con cajones, vidrieras, puertas o sin ellas, realizadas en madera de nogal, ébano y pino principalmente ${ }^{42}$, todos ellos valorados en 6.027 reales de plata ${ }^{43}$. A este mobiliario hay que añadir los numerosos textiles que formaban parte del ajuar de la casa, toallas, cobertores para la cama, colgaduras y doseles, sobresaliendo particularmente un cobertor de China y un terliz bordado de imaginería de la India. Asimismo, dentro de este apartado, es relevante la ropa del propio Francisco Manso y los vestidos de su mujer, así como los tejidos, sedas, damascos y algodón ${ }^{44}$ que, junto a la ropa blanca, superaban los 8.000 reales de plata ${ }^{45}$.

La posesión de estas suculentas vestimentas, entre las que podemos encontrar una gabardina de paño negra, una capa de Segovia o un vestido de damasco ${ }^{46}$, son testigos, no sólo de su ya mencionada riqueza, sino también del elevado concepto que tuvo de sí mismo y de su propia actividad ${ }^{47}$. Y es que el uso por parte de los pla-

40 Para profundizar en el conocimiento de este artista, véanse, entre otros, los siguientes trabajos: AGULLÓ Y COBO, Mercedes, Noticias sobre pintores madrileños de los siglos XVI y XVII, Granada, Universidad de Granada, 1978; AGULLÓ Y COBO, Mercedes, "El escultor Morelli y sus hijos en la corte española", Boletín del Museo Nacional de Escultura, 6 (2002); GARCÍA CUETO, David, Seicento boloñés y siglo de oro español, Madrid, Centro de Estudios Europa Hispánica, 2006; ATERIDO, Ángel, El final del Siglo de Oro. La pintura en Madrid en el cambio dinástico 1685-1726, Madrid, CSIC-Coll\&Cortes, 2015; PÉREZ SÁNCHEZ, Alfonso, Pintura barroca en España 1600-1750, Madrid, Cátedra, 1992.

41 Juan de Orea tasó junto a Damian Zurreño y Bernabé Ruiz las obras del platero real Simón Navarro, véase: MARTÍN, Fernando, "El cargo de platero real", en RIVAS CARMONA, Jesús (coord.), Estudios de Platería: San Eloy 2001, Murcia, Editum, 2001, pp. 159-160.

42 A.H.P.M. Protocolo no 10973, fol. 962 v.

43 A.H.P.M. Protocolo $\mathrm{n}^{\mathrm{o}} 10973$, fol. $984 \mathrm{v}$.

44 A.H.P.M. Protocolo $n^{\circ} 10973$, fol. 964 r a 965 r.

45 A.H.P.M. Protocolo n ${ }^{\circ} 10973$, fol. 993 v y 987 r.

46 A.H.P.M. Protocolo n ${ }^{\circ} 10973$, fol. 965 r.

47 En este momento los plateros reivindicaron la desvinculación de su oficio de las consideradas Artes mecánicas argumentando que ellos hacían uso del diseño para la ejecución de sus piezas, al igual que los pintores, los escultores y los arquitectos. Desconocemos si Manso era o no ajeno a estos planteamientos, pero, el hecho de poseer los ya citados instrumentos de medida en su taller y vestir semejante indumentaria, nos conducen a pensar que sí. Para un estudio más detallado sobre esta lucha por la inclusión de la Platería entre las Artes liberales, véanse, entre otros, los siguientes trabajos: BELDA NAVARRO, Cristóbal, "Sin Sciencia e noticia de las artes liberales", en RIVAS CARMONA, Jesús (coord.), Estudios de Platería: San Eloy 2016, Murcia, Editum, 2016, p. 122; GÁLLEGO SERRANO, Julián, El pintor de artesano a artista, Granada, Universidad de Granada, 1976; MARTÍN GONZÁLEZ, Juan José, El artista en la sociedad española del siglo XVII, Madrid, Cátedra, 1984 y HELWIG, Karin, La literatura artística española del siglo XVII, Madrid, Antonio Machado, 
teros de este tipo de prendas, confeccionadas con las telas más ricas del mercado, fue tomado como una manifestación exterior de su concepción como artistas, tornandose un paso imprescindible para dignificar su $\operatorname{arte}^{48}$.

El pintor flamenco Andrés Smith se ocupó de la tasación de su colección pictórica, en la que además se incluían ciertas esculturas y un espejo. La cifra alcanzada fue de 3.702 reales, bastante baja si tenemos en cuenta que en el inventario se registraron un total de 56 piezas, siendo 31 de ellas pinturas. En efecto, fueron tasadas casi en su totalidad en un precio que estuvo lejos de ser elevado, pues osciló entre los 50 y 100 reales, dato que, unido a la ausencia de referencia alguna respecto a su autoría ${ }^{49}$, nos hace suponer que el conjunto procedería de talleres de artistas de segunda o tercera, y su calidad sería más bien modesta.

Abundan, como venía siendo lo habitual en aquel periodo, las pinturas de temática religiosa, principalmente las dedicadas a los santos y a la Virgen, cuyo papel en la Iglesia Católica fue reivindicado tras la celebración del Concilio de Trento. En la colección de Francisco Manso se encontraban, entre otras, "una pintura de Nuestra Señora en tabla pequeña con San Joseph y el niño, un San Gerónimo con sus adornos de bronce, una pintura del angel de la Guarda con marco de peral, otra pintura de San Gerónimo a modo de retablo en tabla, una de San Francisco de bara y quarta de alto con su marco negro y otra pintura de San Isidro del mismo tamaño"s0; así como varias imágenes de María bajo diversas advocaciones, una pintura de Nuestra Señora de la Soledad, más otra pintura de Nuestra Señora de la Contemplación de bara y media con marco negro y dorado, más una imagen de Nuestra Señora de la Conzepcion, mas una pintura de Nuestra Señora del Populu en lamina con marco de ebano" 51 . Pese a los escasos datos que aporta Smidt, pues se limitó a enumerarlas, informando sólo en contadas ocasiones sobre su tamaño, no nos resulta difícil entrever que se trataba de una modesta colección de las tradicionales pinturas de devoción de pequeño formato, realizadas en serie para el uso personal, tan habituales en aquel momento ${ }^{52}$.

1999. No se puede olvidar que los aspirantes a maestros plateros debían de superar una serie de pruebas, entre las que se encontraba la formulación de un dibujo de una pieza de platería o joyería, que posteriormente debían de materializar, véase, entre otros trabajos: GARCÍA GAÍNZA, María Concepción, Dibujos antiguos de los plateros de Pamplona, Pamplona, Universidad de Navarra, 1991; COTS MORATÓ, Francisco de Paula, El examen de maestría en el arte de plateros de Valencia: los libros de dibujos y sus artifices (1505-1882), Valencia, Delegación de Cultura, 2004 y MÉNDEZ HERNÁN, Vicente, "Aprendices, oficiales, maestros plateros y dibujos de examen en el Madrid de finales del siglo XVII y comienzos del XIX”, en RIVAS CARMONA, Jesús (coord.), Estudios de Platería: San Eloy 2015, Murcia, Editum, 2015, pp. 281-302.

48 Sirva de ejemplo y modelo para ello el retrato del platero Juan de Arfe situado en su obra De Varia conmensuración para la Esculptura y Architectura, ejemplo notable de la estima que el platero tenía de sí mismo. Véanse, entre otros estudios: PORTÚS PÉREZ, Javier, Metapintura: un viaje a la idea del arte en España, Madrid, Museo Nacional del Prado, 2016, p. 147.

49 Tan sólo se hace mención de una lámina con la imagen de la Encarnación cuyo autor es, según señala Smith, Carreño. Se refiere indudablemente a Carreño de Miranda (1614 - 1685), pintor de cámara de Carlos II. Fuera o no la lámina de este artista, lo cierto es que la calidad debía superar con creces al resto dado que su precio se dispara notablemente, se tasó en 550 reales. A.H.P.M. Protocolo ${ }^{\circ}{ }^{10973}$, fol. 990 r.

50 A.H.P.M. Protocolo n 10973 , fol. 998 v.

51 Se refiere a la basílica de Santa María del Popolo, situada en una de las plazas principales de Roma. Con toda probabilidad esta lámina fue enviada por su hijo desde dicha ciudad, donde él, como ya señalamos al inicio de nuestro estudio, era clérigo del colegio de Santiago.

52 CARLOS VARONA, María Cruz de (coord.), La imagen religiosa en la Monarquía hispánica: usos y espacios, Madrid, Casa de Velázquez, 2008; CALVO SERRALLER, Francisco. Los géneros de la pintura, Madrid, Taurus, 2005. 
Pese a esta preeminencia de la temática religiosa parece ser que Francisco Manso también participó del gusto de la época y adquirió algún ejemplar de pintura de género, pues en la almoneda se cita "un retrato de un estudiante, más un retrato de un niño, así como quatro floreros de a tres quartas con marcos negros "53. Teniendo en cuenta su coste, ninguno de ellos superó los 200 reales, nos hacen suponer que continuamos con la tónica que ya señalábamos cuando hacíamos referencia a su colección de pintura religiosa, es decir, se trataría de obras modestas y de escasa calidad ${ }^{54}$.

Dentro del apartado dedicado a las pinturas, se incluyeron también ciertas esculturas, la mayoría de temática religiosa, como atestiguan un San Jerónimo con sus adornos de bronce, una Inmaculada Concepción de alabastro, tasada en ciento diez reales, y una imagen de Nuestra Señora en cera, entre otras piezas. Aunque tienen cierto interés dado los materiales empleados, alabastro y cera, llama poderosamente la atención un Cristo sobre peana grande de pino guarnecida de conchas y caracolas, con una cruz de ébano con sus remates de bronce dorados de molido ${ }^{55}$. También, resulta interesante la presencia en el inventario de diversas imágenes de un hombre a caballo, un galgo y cuatro leones, entre otros animales, todos en bronce, lo que debe entenderse como una serie de objetos decorativos que no deben vincularse a su profesión, puesto que éstos se encontraban dentro del contenido de su casa ${ }^{56}$.

Uno de los apartados más interesantes del inventario por la posibilidad que ofrece para acercarse al oficio de platero, y por tanto a la actividad en su taller, es la relación de objetos vinculados a la profesión ${ }^{57}$. Entre ellos se encontraban todos aquellos útiles necesarios para el desempeño del ejercicio del Arte de la Platería, sirvan de testigos unas tenazas, fuelles, martillos, hierros y tijeras, de todas las medidas y proporciones. A esta serie de herramientas de carácter más artesanal hay que sumar otros objetos, como una escuadra, un cartabón y tres compases, instrumentos de cariz más científico, cuyo empleo le hacen presuponer un conocimiento teórico, más allá del mero trabajo manual ${ }^{58}$. Igualmente, es reseñable el mobiliario del taller, compuesto por varias mesas, bancos, sillas, arcones, estantes y aparadores para la exposición de las piezas de plata, dado que no hay que olvidar que el taller se encontraba precedido

53 Según nos consta, la pintura de bodegones y floreros tuvo gran éxito en el Madrid del Seiscientos, para un estudio más detallado sobre el tema, véanse, entre otros trabajos: CALVO SERRALLER, Francisco, Flores españolas del Siglo de Oro: la pintura de flores en la España del siglo XVII, Madrid, Fundación Amigos del Museo del Prado, 2002. Otros estudios vinculados con el tema son: PÉREZ SÁNCHEZ, Alfonso, Pintura española de bodegones y floreros de 1600 a Goya, Madrid, Ministerio de Cultura, Dirección General de Bellas Artes y Archivos, 1983; PÉREZ SÁNCHEZ, Alfonso, Pintura española de bodegones y floreros, Catálogo Exposición, Tokio, The National Museum of Western Art, 1992.

54 Que los plateros tuvieran pinturas en sus casas era una práctica normal, tanto en España como en Europa. Si bien, la diferencia está en el tipo de lienzos que poseían, dado que en todas las casas era normal encontrar imágenes de santos, lo que no supondría ninguna diferenciación. Sin embargo, otros plateros si contaban con una importante colección de pinturas, como el contemporáneo platero flamenco asentado en Bolonia, Joannes Jacobs, quien contaba con diversas obras de la importante escuela boloñesa del siglo XVII, formada entre otros por Guido Reni, véase: BERTOLI BARSOTTI, Anna Maria, Joannes Jacobs Bruxellensis 1575-1650: orefice a Bologna e fondatore del Collegio dei Fiamminghi, Bologna, Bononia University Press, 2014.

55 A.H.P.M. Protocolo $\mathrm{n}^{\circ} 10973$, fol. $963 \mathrm{r}$ y v.

56 A.H.P.M. Protocolo ${ }^{\circ}$ 10973, fol. 963 r.

57 Este aspecto ha suscitado el interés de una amplia gama de investigadores, véanse entre otros trabajos: MARTÍN VAQUERO, Rosa, "Un taller vitoriano de Plateros del siglo pasado que aún pervive: instrumentos y herramientas que se conservan", Ondare: cuadernos de artes plásticas y monumentales, 8 (1991), pp. 217 246; BARRÓN GARCÍA, Aurelio A., "El taller de los plateros burgaleses a la luz de los inventarios", Estudios mirandeses: Anuario de la Fundación cultural "Profesor Cantera Burgos”, 17 (1997), pp. 129-166.

58 A.H.P.M. Protocolo $n^{\circ}$ 10973, fol. 967r. 
por una tienda donde se exponían aquellos objetos listos para su venta ${ }^{59}$. En definitiva, las herramientas y objetos necesarios para el desarrollo del oficio fueron tasadas en los 9.600 reales de plata ${ }^{60}$.

En este sentido, las piezas listas para su venta se puede dilucidar como su actividad estaba especialmente enfocada a la platería religiosa, muy demandada por los templos madrileños tras la proliferación de tipologías y objetos necesarios para la celebración de la Eucaristía tras la Contrarreforma ${ }^{61}$. Así, tenía ya listas para su venta diferentes piezas y joyas por valor de 57.756 reales de plata ${ }^{62}$, como un incensario con cadenas y su naveta a juego, seis cálices con sus patenas, dos azafates con asas grandes y cincelados, y un brasero grande. Si bien, debía de haber un alto número de objetos, ya que se deja entrever en la documentación que hay más hechuras de plata, así nuevas como quebradas para fundir, como vinajeras, tembladeras, vasos, calderillas, medallas, tachuelas ... "que todas por ser tantas y de tan diversas maneras y echura no se apodido mencionar ni pesar cada una de por si..." ${ }^{63}$. Todo ello hizo un montante de quinientos noventa y cinco marcos, cinco onzas y dos ochavas, tal y como rubricaba con su presencia el contraste Manuel Mayers ${ }^{64}$. No entraron en este lote otra serie de piezas que por su valor fueron consideradas de forma independiente, por ejemplo, una petaca de filigrana de plata, una bandeja de plata ochavada, dorada al interior y con diferentes esmaltes de figuras y partes de porcelana. Mismo tratamiento recibieron las joyas más menudas, como diversas sortijas y arracadas, entre las cuales cabe citar una sortija de oro guarnecida con dos diamantes triangulares y una esmeralda en medio y otra con tres esmeraldas y, entre los pendientes, dos arracadas de oro grandes decoradas con una rosa en el medio. Junto a sortijas y pendientes el platero Manso confeccionaba también otro tipo de joyas más elaboradas, como piezas de oro de filigrana con ocho rosas guarnecidas de perlas y en medio de ellas una imagen, preferentemente de San Antonio de Padua, de la Santa Mujer Verónica, de la Inmaculada de Concepción y de la Virgen del Sagrario entre otras. Prosigue la relación de objetos con distintos tipos de joyas, entre los que se puede citar una venera de oro esmaltada en blanco y negro de porcelana con una cruz de Alcántara y guarnecida con diez rubíes ${ }^{65}$. Todas estas piezas demuestran cómo, además de platero, estaba especializado en joyería, ampliando así la gama de productos puestos a la venta y asegurándose un mayor mercado con el que adquirir unas ganancias más elevadas ${ }^{66}$.

No obstante, la actividad profesional de Manso seguramente no se limitaría exclusivamente a la hechura y venta de piezas de plata y joyas, sino que llevaría a cabo otra serie de acciones destinadas a incrementar notablemente sus fondos. En este sentido, el inventario arroja una importante documentación al relacionarse una

\footnotetext{
A.H.P.M. Protocolo n ${ }^{\circ} 10973$, fol. $967 \mathrm{v}$.

A.H.P.M. Protocolo $n^{\circ}$ 10973, fol. 997r.

61 CRUZ VALDOVINOS, José Manuel, "La función de las artes suntuarias en las catedrales: ritos, ceremonias y espacios de devoción”, en CASTILLO OREJA, Miguel Ángel (coord.), Las catedrales españolas en la Edad Moderna: aproximación a un nuevo concepto del espacio sagrado, Madrid. Fundación BBVA, 2001, pp. 149170; RIVAS CARMONA, Jesús, "El impacto de la Contrarreforma en las platerías catedralicias", en Estudios de Platería: San Eloy 2003, Murcia, Editum, 2003, pp. 515-536.

62 A.H.P.M. Protocolo $\mathrm{n}^{\mathrm{o}} 10973$, fol. $984 \mathrm{v}$.

63 A.H.P.M. Protocolo n ${ }^{\circ} 10973$, fol. 968 v.

64 A.H.P.M. Protocolo $n^{\circ}$ 10973, fol. 969 r.

65 A.H.P.M. Protocolo $\mathrm{n}^{\circ} 10973$, fol. $970 \mathrm{r}$ a 972 v.

66 A.H.P.M. Protocolo $\mathrm{n}^{\circ}$ 10973, fol. 969 r y v.
} 
serie de objetos que habían sido empeñados y que se encontraban en su posesión, por ejemplo, una caja de plata dorada del propio Jerónimo Montero de Espinosa o un salero de plata de Catalina Fernández, actividad con la que el artífice encontró otra fuente de financiación ${ }^{67}$. Por otro lado, la documentación también recoge una larga lista de deudores, principalmente miembros del Arte de la Platería, como son Juan Ortiz, quien adeudaba con él veinticuatro doblones; Juan Esteban, quien le debía cuarenta y ocho reales de plata y, entre otros, Francisco Gutiérrez, Manuel Gutiérrez, Bernardo de Carrión o Juan de Parada, todos ellos artífices del gremio. Si bien, entre los deudores más significativos, lo que demuestra para que tipo de personas trabajaba el platero, destaca el nombre del Príncipe de Parma, quien debe corresponderse con el de Alejandro Farnesio. Éste adeudaba al platero varios pagos que superaban los dos mil reales ${ }^{68}$. No obstante, Manso también había dejado sin pagar una serie de deudas, que en cierto modo también reflejan algunos rasgos personales del platero. Por ejemplo, son comunes los pagos pendientes a mercaderes de paños y sedas, como los seiscientos reales que debía al mercader de sedas Castaño o los noventa y tres que tenía pendientes con el sastre Juan Jiménez. También son recurrentes los pagos a diferentes individuos de la zona por la compra de alguna pieza de plata o joyas menudas, destinadas posiblemente a la posterior venta en su tienda o a la fundición, por ejemplo, a Antonio Rodríguez debía siete reales por una pila de plata y a Andrés Felipe seis más por una sortija de oro ${ }^{69}$.

A pesar de los numerosos objetos hallados en el inventario de los bienes del maestro, resulta curioso que no contara con una pequeña biblioteca, "verdadera cantera para la inspiración", y es que durante el periodo que nos ocupa, era entendida por los artistas "no sólo como elemento de formación sino como medio para el estudio y el trabajo"70. El hecho de no poseer ni un solo volúmen nos conduce a pensar que se trataba de un artista analfabeto ${ }^{71}$, ya que de lo contrario hubiera poseído, y más si tenemos en cuenta que gozaba de una acomodada posición económica, de ciertos volúmenes que se hacían imprescindibles en la biblioteca de cualquier artista erudito, como las Vidas $^{72}$ de Giorgio Vasari o alguno de los diez tomos de Arquitectura ${ }^{73}$ de Vitrubio, entre otros ${ }^{74}$. No obstante, no resultaría extraño que Francisco Manso hubiese adquirido cierto bagaje cultural a través de la visualización de estampas de otros colegas de oficio, o bien en tertulias celebradas en su círculo más cercano, sobre todo si consideramos su estrecha relación con Manuel Mayers, quien poseía

67 A.H.P.M.. Protocolo n ${ }^{\circ}$ 10973, fol. 973 v y 974 r.

68 A.H.P.M. Protocolo $n^{\circ} 10973$, fol. 975 r y v.

69 A.H.P.M. Protocolo ${ }^{\circ}$ 10973, fol. $977 \mathrm{r}$ a $978 \mathrm{v}$.

70 NAVARRETE PRIETO, Benito, La pintura andaluza del siglo XVII y sus fuentes grabadas, Tesis doctoral, depósito Universidad Complutense de Madrid, 2003, p. 102.

71 Para el estudio de la alfabetización de los artistas, véanse, entre otros ejemplos: CIPOLLA, Carlo M., Educación y desarrollo en Occidente, Esplugues de Llobregat, Ariel, 1970, pp. 63-64; MARTÍN GONZÁLEZ, Juan José. El artista en la sociedad... op. cit., p. 222- 224.

72 VASARI, Giorgio. Las vidas de los más excelentes arquitectos, pintores y escultores italianos desde Cimabue a nuestros tiempos. Selección y edición de Ana Ávila, Madrid, Cátedra, 2005.

73 VITRUBIO POLIÓN, Marco Lucio, Los diez libros de Arquitectura/ Introducción por Delfín Rodríguez Ruiz; versión española de José Oliver Domingo, Madrid, Alianza, 1995.

74 MARTÍN GONZÁLEZ, Juan José, "Bibliotecas de artistas: una aplicación de la estadística", Academia: Boletín de la Real Academia de Bellas Artes de San Fernando, 61 (1985), pp. 123-144; SOLER I FABREGAT, Ramón, "Libros de arte en bibliotecas de artistas españoles (siglos XVI- XVIII): aproximación y bibliografía", Locus Amoenus, 1 (1995), pp. 145-164. 
una brillante biblioteca ${ }^{75}$. De ser así, Francisco Manso se englobaría dentro de esa nómina de artistas que se movieron en círculos selectos y satisficieron la demanda de una clientela de gusto refinado pero que jamás supieron de letras más allá de realizar su propia rúbrica ${ }^{76}$.

En definitiva, el hallazgo del testamento, inventario y la almoneda de bienes ha sacado a la luz la figura de un platero desconocido hasta ahora, cuyo análisis nos ha permitido conocerlo más de cerca y resolver numerosas incógnitas acerca de sus orígenes, sus posesiones y sus intereses personales. Bien es cierto que hemos echado en falta más referencias vinculadas a su trayectoria profesional (contratos de obras, clientes...), que, como hemos venido señalando, nos hubieran resultado de gran utilidad para vislumbrar la categoría que alcanzó así como posición en el ámbito artístico del momento. No obstante, el haber trabajado al servicio de la IX duquesa Béjar, su vínculo con Manuel Mayers, así como el importante patrimonio que dejó tras su fallecimiento nos conducen a pensar que gozó de gran prestigio. Futuros hallazgos en los archivos nos darán la oportunidad de continuar perfilando su figura y conocer con mayor detalle el papel que desempeñó Francisco Manso en el ambiente artístico madrileño de la segunda mitad del XVII.

BARRIO MOYA, José Luís, “La librería de Manuel Mayers Caramuel...”, op. cit., pp. 181-210.

76 No resulta extraño dar con artistas de reconocido prestigio con una selecta clientela que, sin embargo, se mantuvieron analfabetos; el ejemplo más significativo en el periodo que nos ocupa fue el pintor Antonio de Pereda, del que Antonio Palomino dice que "Tuvo (...) una librería admirable; y especialmente de la Pintura, en varios idiomas, tenia libros excelentes: y con todo esto no sabia leer, ni escribir, cosa indigna, y mas en hombre de esta clase: de suerte, que para firmar un quadro, le escribian la firma en un papel, y él la copiaba; y gustaba de que los discípulos, y algunos amigos le leyesen historias, y especialmente las que habia de pintar; y de este modo disfrutaba de la librería". Véase PALOMINO DE CASTRO Y VELASCO, Antonio, El museo pictórico y escala óptica, Madrid, Imprenta de Sebastián de Sancha, 1747, p. 549; para profundizar más en la figura de este pintor véanse, entre otros, los trabajos que se citan a continuación: Don Antonio de Pereda (1611 - 1678) y la pintura madrileña de su tiempo, cat. exp., Madrid, Ministerio de Cultura, 1978; ATERIDO FERNÁNDEZ, Ángel, "Mecenas y fortuna del pintor Antonio de Pereda", Archivo Español de Arte, 279 (1997), pp. 271- 284; CHERRY, Peter, Arte y naturaleza. EL bodegón español en el siglo de oro, Madrid, Fundación de Apoyo a la Historia del Arte Hispánico, 1999, pp. 220-229. 